\title{
ROTATING FIELD EDDY CURRENT PROBE FOR CHARACTERIZATION OF CRACKING IN NON-MAGNETIC TUBING
}

$$
\text { CONF-990701- - }
$$

T. E. Capobianco

July 1998

DISTRIBUTION OF THIS DOCUNENT BS UARATED ph

\section{NOTICE}

This report was prepared as an account of work sponsored by the United States Government. Neither the United States, nor the United States Department of Energy, nor any of their employees, nor any of their contractors, subcontractors, or their employees, makes any warranty, express or implied, or assumes any legal liability or responsibility for the accuracy, completeness or usefulness of any information, apparatus, product or process disclosed, or represents that its use would not infringe privately owned rights. 


\section{DISCLAIMER}

This report was prepared as an account of work sponsored by an agency of the United States Government. Neither the United States Government nor any agency thereof, nor any of their employees, make any warranty, express or implied, or assumes any legal liability or responsibility for the accuracy, completeness, or usefulness of any information, apparatus, product, or process disclosed, or represents that its use would not infringe privately owned rights. Reference herein to any specific commercial product, process, or service by trade name, trademark, manufacturer, or otherwise does not necessarily constitute or imply its endorsement, recommendation, or favoring by the United States Government or any agency thereof. The views and opinions of authors expressed herein do not necessarily state or reflect those of the United States Government or any agency thereof. 


\section{DISCLAIMER}

Portions of this document may be illegible in electronic image products. Images are produced from the best available original document. 


\title{
Rotating Field Eddy Current Probe for Characterization of Cracking in Non-Magnetic Tubing
}

TE Capobianco

Lockheed Martin

Schenectady, NY

\begin{abstract}
A rotating field eddy current probe was built and tested for use in small diameter, nonmagnetic tubing. The rotating field probe is a driver/pickup style with two orthogonally wound drive coils and a pancake pickup coil. The driver coils are excited by two sine waves $90^{\circ}$ out of phase with each other. The physical arrangement of the drive coils and the $90^{\circ}$ phase shift of the excitation waveforms creates a field which rotates in the test piece under the drive coils.

Preliminary tests on electrical discharge machined (EDM) notches show that phased based estimates of notch depth are possible. Probes currently used for detection of cracks in tubing produce responses that have proven unreliable for estimating defect depths. This recently developed version of the rotating field eddy current probe produces a bipolar response in the presence of a crack or a notch. Typically, the phase angle of a bipolar eddy current response is easily identified and measured and is used extensively for estimating depths of volumetric defects. Data are shown relating the phase angle of the rotating field probe's bipolar response to the depth of circumferential EDM notches.
\end{abstract}

\section{Background}

Bipolar probe responses are typically seen using dual bobbin probes on volumetric tube defects, such as pitting and wastage. The phase angle of this response generally has a consistent relationship to the defect depth, is easily identified and measured, and is used extensively for estimating volumetric defect depths.

Detection and sizing of tube cracking has been more problematic. Dual bobbin probes have had some success with axial crack detection, but circumferential crack detection is not possible for all but the largest cracks. Improved circumferential crack detection probes have come in the form of arrays of surface riding coils and pancake coils that are mechanically rotated in the tube. More recently, the Zetec plus point probe has been successfully deployed in commercial applications for crack detection in any orientation. Crack sizing, however, remains difficult in part because of the lack of a consistent feature in the data on which to base a depth estimate.

The rotating field probe is a driver/pickup style with two orthogonally wound drive coils and a pancake pickup coil. The driver coils are excited by two sine waves $90^{\circ}$ out of phase with each other. The physical arrangement of the drive coils and the $90^{\circ}$ phase shift of the excitation waveforms creates a field which rotates in the test piece under the drive coils. Previous experiments using a rotating field eddy current probe in this configuration $[1,2]$ have demonstrated a bipolar response to cracks and notches. 
These experiments were performed using relatively large excitation coils, wound on a nearly cubic 2 inch coil form, with a 0.5 inch diameter pickup coil on flat plate specimens.

The rotating field probe used for the work reported here is based on a modified Zetec plus point probe used for the inspection of 0.5 inch outside diameter (OD) tubing. The advantage of using the plus point probe is that it is a commercially produced probe with a pair of orthogonally wound coils A pancake pickup coil was wound on the existing probe housing. This modified probe produces and detects the rotating eddy current field. It is mounted on a probe body that rotates physically in the tube. Thus, not only does the field in the test piece rotate under the probe coils, but the probe coils also rotate in the tube. The unique aspects of the measurements described here are the result of the rotation of the induced field under the probe coils.

\section{Discussion}

Figure 1 shows a schematic of the rotating field probe transducer. In this experiment, the driver coils (coil 1 and coil 2 in the figure) are the coils of a Zetec plus point probe. These coils are wound orthogonally. The probe's magnetic field is applied to the test piece at one of the intersecting areas of the coils. The pickup coil was wound in a groove machined into the plastic housing of the plus point probe.

Figure 2 shows two sinusiodal waveforms which are $90^{\circ}$ out of phase with each other. Because of the combination of the orthogonal coils and the $90^{\circ}$ phase shifted excitation, the direction of the induced currents rotate $360^{\circ}$ with respect to the driver coils. This rotation occurs at the frequency of the excitation waveforms.

Figure 3 shows a block diagram of the experimental setup which consists of a Zetec MIZ-30 eddy current data acquisition system, an external ac power supply, and the rotating field probe. The external power supply is triggered from the MIZ-30 probe drive signal and supplies a waveform that is matched in frequency, amplitude, and duration but is shifted by $90^{\circ}$ electrically. The probe coil assembly is mounted on a probe head and motor unit designed for driver/pickup applications in 0.5 in. OD tubing with 0.047 in. wall thickness.

In the configuration just described, the rotating field probe is self-nulling, that is, there is no pickup coil output in the absence of a defect. The excitation current and the induced eddy current are parallel to the plane of the pickup coil. The pickup coil only detects out of plane, induced-field components caused by the presence of a defect. This makes the probe relatively insensitive to noise producing conditions such as liftoff and sensitive to defects in any orientation. Only results from circumferential notches are reported here, but measurements on axial notches were also performed successfully.

\section{Results}

Figure 4 shows rotating field probe measurements made on a sample of Inconel Alloy 600 tubing. The tubing has an outside diameter of $0.5 \mathrm{in}$. and a nominal wall thickness of 0.047 in. The tube contains circumferentially oriented electrial discharge machined (EDM) notches. The notch widths are approximately 0.010 in. with a circumferential extent of $45^{\circ}$. 
The notch depths are given as a percentage of wall thickness and vary between $100 \%$ to $20 \%$ in steps of $20 \%(100,80,60,40,20)$. The excitation frequency shown is $210 \mathrm{kHz}$. Because the data from the $20 \%$ notch is in the noise, this response is not shown. The data show a bipolar signal at the center of the notch response. Away from the center, the response is primarily either a positive or negative going signal. This can be seen in the strip chart displays shown on the left of each screen print.

Figure 5 shows the behavior of the notch response with changing frequency. The frequencies shown are 300,210 , and $100 \mathrm{kHz}$. Because of the change in eddy current skin depth with frequency, a change in phase of the indication is expected and observed as the test frequency decreases. Here the signal rotates counterclockwise with lower frequency, as expected.

\section{Conclusions}

The rotating field eddy current probe was successfully scaled down for use in detecting OD initiated flaws in $0.5 \mathrm{in}$. diameter, non-magnetic tubing. The probe produces a bipolar response on circumferential EDM notches. The phase angle of this response is easily identified and measured. The phase of the response changes with flaw depth and also exhibits the expected response to changes in frequency. The data presented here indicate that the rotating field probe can be used to estimate the depth of circumferential crack-like flaws.

Notches with depths as shallow as $40 \%$ of the wall thickness were clearly measured. The $20 \%$ notch, which is easily detected with the conventional plus point probe, was not clearly

discernible with this probe. However, these measurements were made with a proof-ofprinciple probe made from materials on hand, and was not optimized.

\section{References}

1. H. Hoshikawa and K. Koyama, "A New ECT Probe with Rotating Direction Eddy Current," Review of Progress in QNDE, Vol. 15A, p. 1091, Plenum Press, New York, 1996.

2. H. Hoshikawa and K. Koyama, "A New Eddy Current Probe Using Uniform Rotating Eddy Currents," Materials Evaluation, Vol. 56, No. 1, p. 85-89, Jan 1998. 


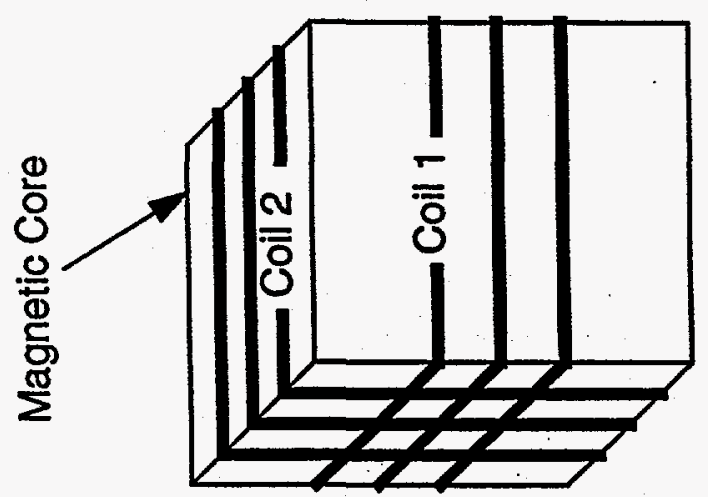

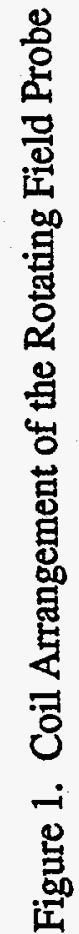

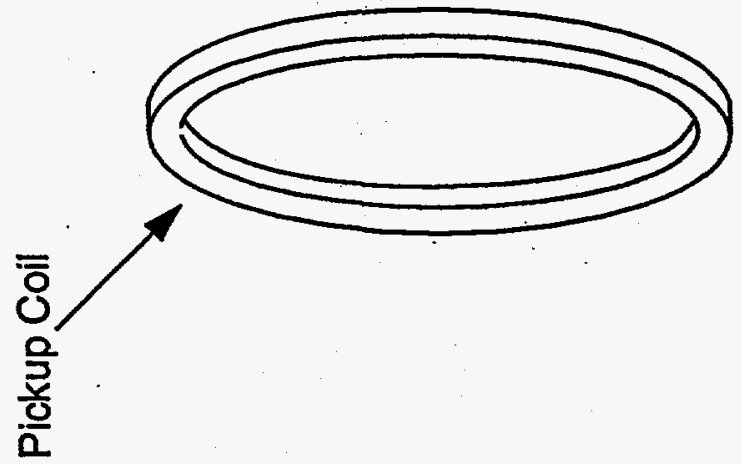




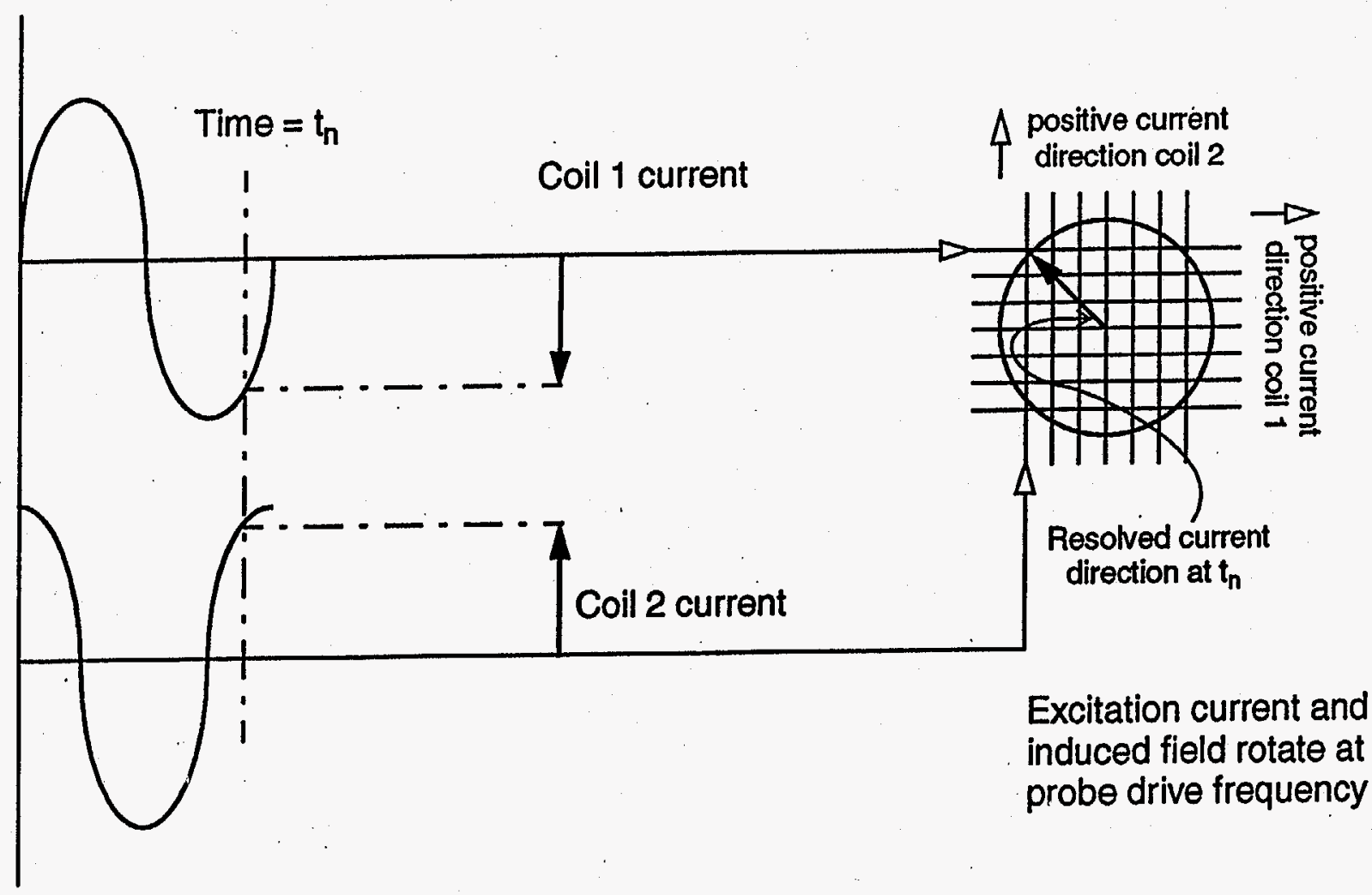

Figure 2. Phased Excitation of Rotating Field Probe 


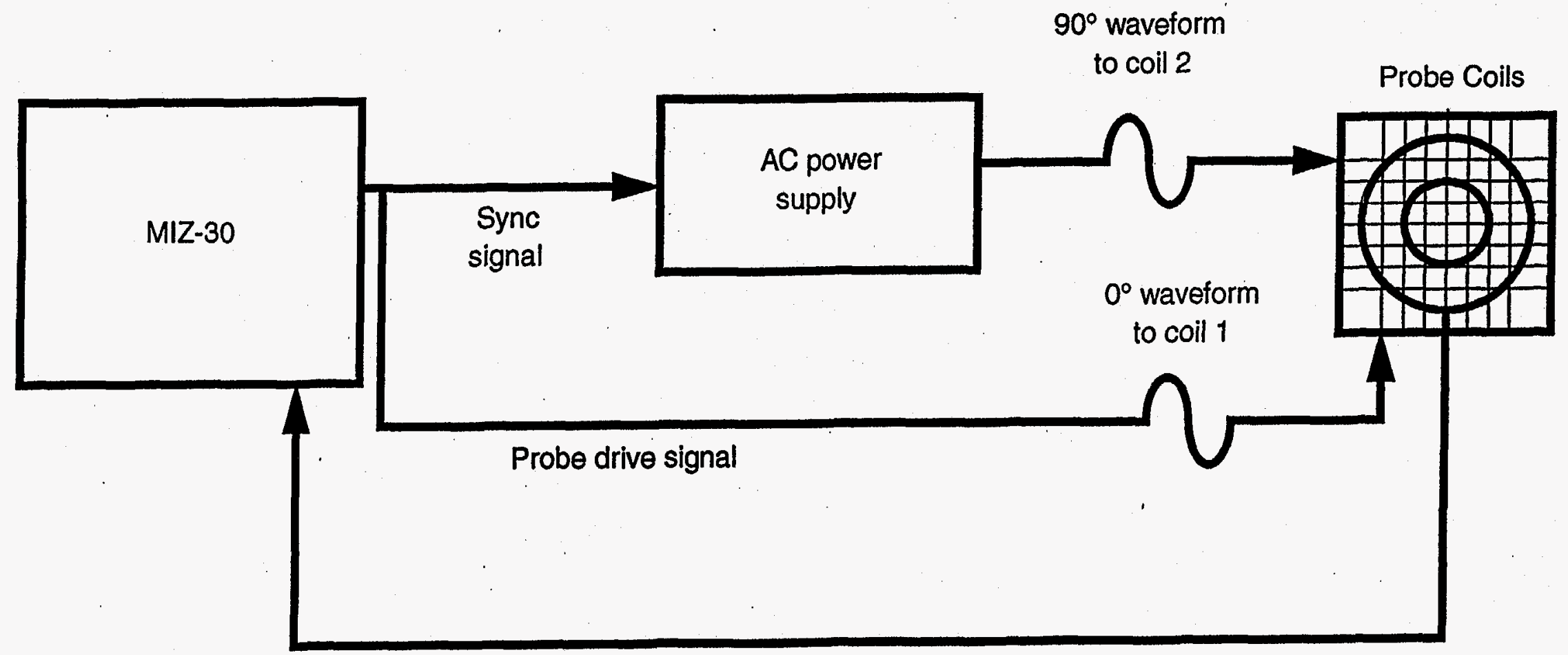

Pickup coil output to MIZ-30 operating in driver/pickup mode

Figure 3. Measurement System Schematic 

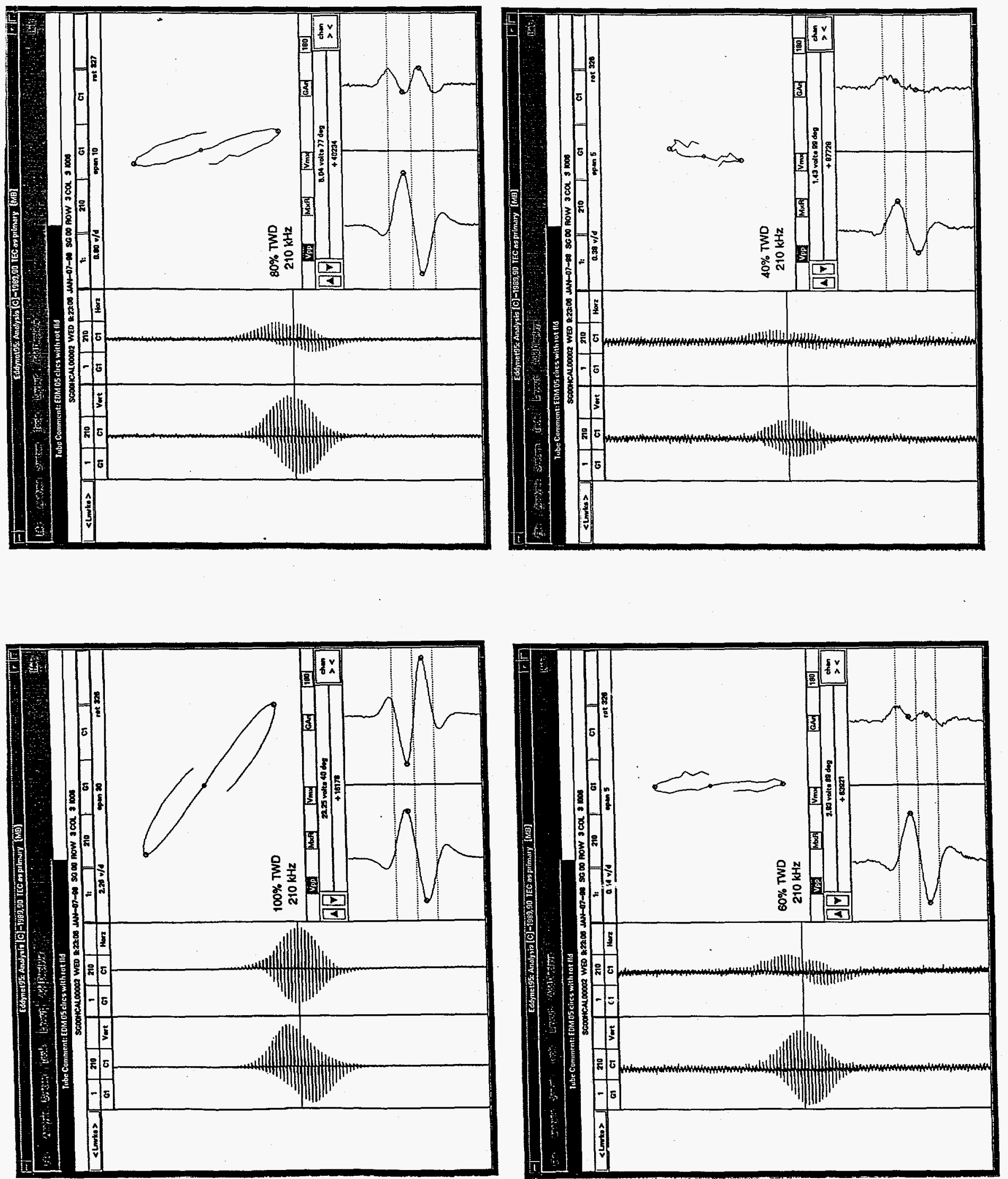

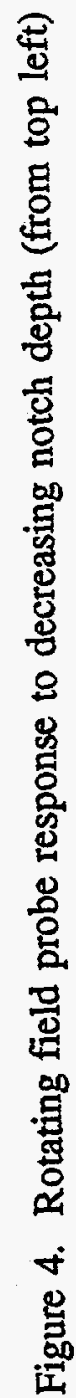



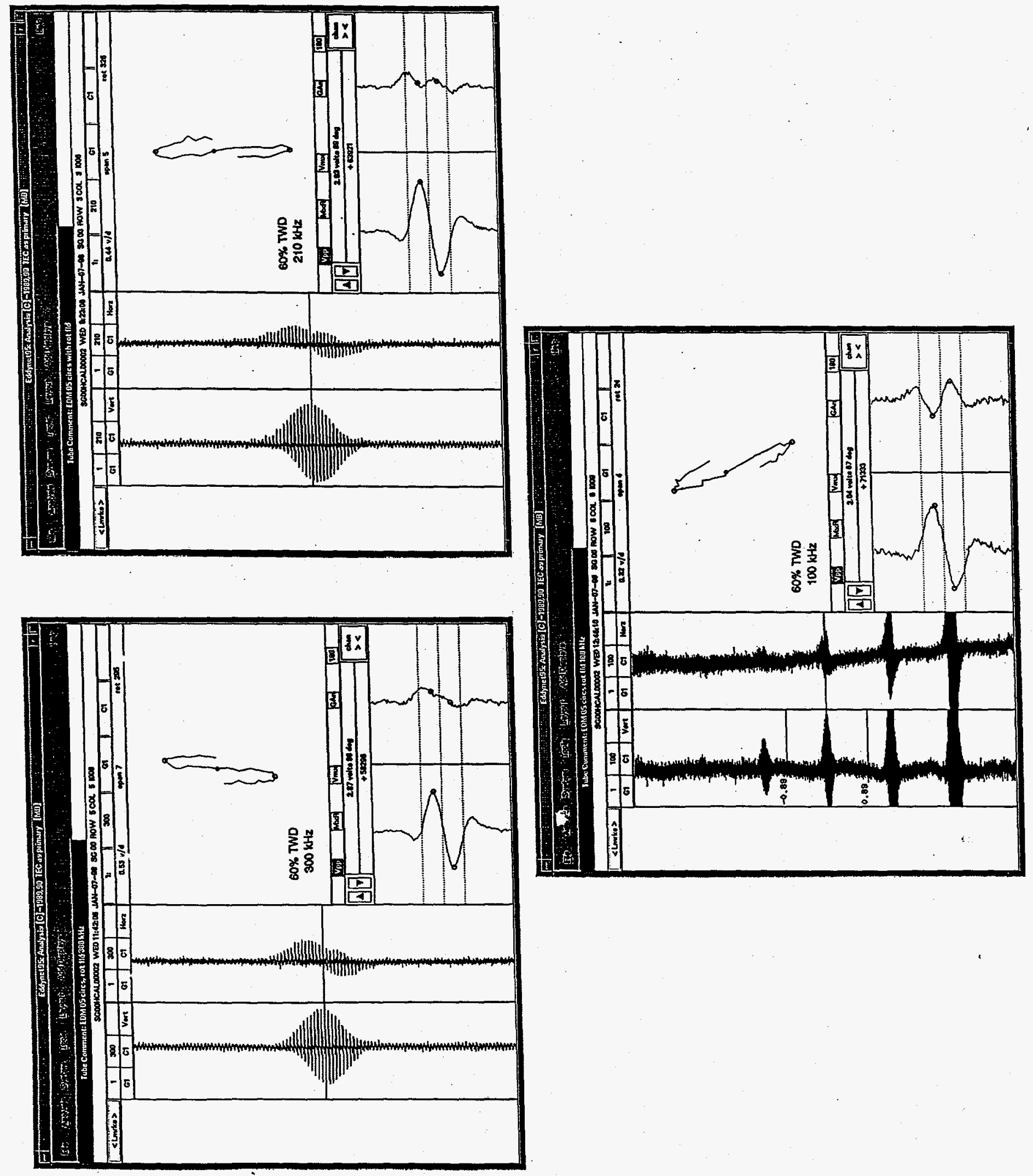

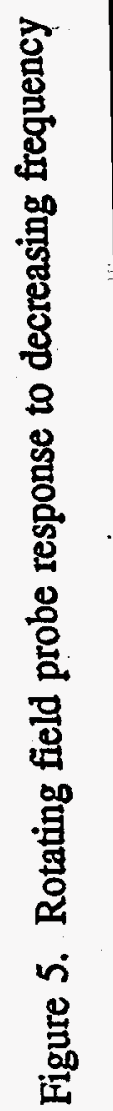

